\title{
Epidemiological risk factors associated with high global frequency of inapparent dengue virus infections
}

\section{Laura Grange ${ }^{1,2}$, Etienne Simon-Loriere ${ }^{1,2}$, Anavaj Sakuntabhai ${ }^{1,2}$, Lionel Gresh ${ }^{3}$, Richard Paul ${ }^{1,2}{ }^{*}$ and Eva Harris $^{4}$ *}

\author{
1 Unité de la Génétique Fonctionnelle des Maladies Infectieuses, Institut Pasteur, Paris, France \\ 2 URA3012, Centre National de la Recherche Scientifique, Paris, France \\ ${ }^{3}$ Sustainable Sciences Institute, Managua, Nicaragua \\ ${ }^{4}$ Division of Infectious Diseases and Vaccinology, School of Public Health, University of California, Berkeley, CA, USA
}

\section{Edited by:}

Scott B. Halstead, International Vaccine Institute, South Korea

\section{Reviewed by:}

Dirk Dittmer, University of North Carolina at Chapel Hill, USA

In-Kyu Yoon, U.S. Army, USA

\section{*Correspondence:}

Richard Paul, Unité de la Génétique Fonctionnelle des Maladies Infectieuses, Institut Pasteur, 28 rue du Docteur Roux, F-75724 Paris Cedex 15, France

e-mail: richard.paul@pasteur.fr; Eva Harris, Division of Infectious Diseases and Vaccinology, School of Public Health, University of California 185 Li Ka Shing Center, 1951 Oxford Street, Berkeley, CA 94720-3370, USA

e-mail: eharris@berkeley.edu
Dengue is a major international public health concern, and the number of outbreaks has escalated greatly. Human migration and international trade and travel are constantly introducing new vectors and pathogens into novel geographic areas. Of particular interest is the extent to which dengue virus (DENV) infections are subclinical or inapparent. Not only may such infections contribute to the global spread of DENV by human migration, but also seroprevalence rates in naïve populations may be initially high despite minimal numbers of detectable clinical cases. As the probability of severe disease is increased in secondary infections, populations may thus be primed, with serious public health consequences following introduction of a new serotype. In addition, pre-existing immunity from inapparent infections may affect vaccine uptake, and the ratio of clinically apparent to inapparent infection could affect the interpretation of vaccine trials. We performed a literature search for inapparent DENV infections and provide an analytical review of their frequency and associated risk factors. Inapparent rates were highly variable, but "inapparent" was the major outcome of infection in all prospective studies. Differences in the epidemiological context and type of surveillance account for much of the variability in inapparent infection rates. However, one particular epidemiological pattern was shared by four longitudinal cohort studies: the rate of inapparent DENV infections was positively correlated with the incidence of disease the previous year, strongly supporting an important role for short-term heterotypic immunity in determining the outcome of infection. Primary and secondary infections were equally likely to be inapparent. Knowledge of the extent to which viruses from inapparent infections are transmissible to mosquitoes is urgently needed. Inapparent infections need to be considered for their impact on disease severity, transmission dynamics, and vaccine efficacy and uptake.

Keywords: dengue, subclinical, inapparent, asymptomatic, infection

\section{INTRODUCTION}

Dengue has become a major international public health concern and is the most important arthropod-borne disease of humans (14). Any of the four antigenically distinct viruses, or serotypes, designated dengue virus (DENV)-1, DENV-2, DENV-3, and DENV-4, belonging to the Flavivirus genus in the family Flaviviridae, can cause dengue fever (DF), an acute viral infection characterized by fever, rash, headache, muscle and joint pain, and nausea, as well as more severe forms of the disease. A possible fifth serotype has recently been detected, but its global significance remains to be seen (5). Occasionally, DF progresses to dengue hemorrhagic fever/dengue shock syndrome (DHF/DSS), a potentially life-threatening illness associated with vascular leakage, hemorrhage, and shock. By contrast, it is increasingly recognized that the majority of DENV infections are subclinical, resulting in insufficient discomfort for clinical consultation (6). This reservoir of infection needs to be addressed.
Over the past decade, the number of dengue outbreaks has escalated (4), and the population at risk is increasing yearly. More than 3.5 billion people are at risk of DENV infection. It has recently been estimated that there are 390 million DENV infections every year, of which up to 96 million are symptomatic (7). This prolific increase has been associated with societal changes such as population growth and increasing urbanization, particularly in tropical cities with poor waste and water management, leading to proliferation of the domestic and peridomestic mosquito species that transmit DENV, Aedes aegypti and A. albopictus. Human migration and international trade and travel are constantly introducing new vectors and pathogens into novel geographic areas $(8,9)$. In addition, it has been suggested that rising temperatures and global climate change may lead to the expansion of the range of major mosquito vectors into new areas, extension of the transmission season in areas with currently circulating DENV, decrease in extrinsic incubation period, and increase in the mosquito spp. 
vectorial capacity $(10,11)$. The potential threat of DENV invasion of continental Europe has recently been illustrated by cases of autochthonous dengue in southern France (12). These cases bear testament to the capacity of local A. albopictus mosquito vector to transmit the virus. This Asian tiger mosquito is the major potential vector of DENV in Europe, although the most important vector world-wide, A. aegypti, was identified in Madeira Island, Portugal, in October 2005. A major epidemic occurred in Madeira in 2012 (13). Autochthonous transmission of DENV in the United States has also been reported intermittently over the past decade in Texas, Hawaii, and Florida $(14,15)$.

International travel will ensure importation of virus into nonendemic countries from regions endemic for dengue. Infected individuals may harbor sufficiently high viral loads to infect mosquitoes prior to the onset of symptoms and thereby introduce the virus into the population. Potentially more important is the epidemiological significance of inapparent, subclinical infections. Travelers may import virus without showing overt clinical symptoms and thus will not be detectable either in the airports or once in the country. There is some suggestion that primary $\left(1^{\circ}\right)$ DENV infections can be majoritarily inapparent in certain outbreaks (16), whereas secondary $\left(2^{\circ}\right)$ infections lead to more severe symptoms even when occurring 20 years later (17). In fact, the longer the interval between heterotypic DENV infections, the higher the case fatality rate (18). The public health consequences of such inapparent infections are considerable, because apparently naïve populations may well have been previously exposed to infections, and once hospital cases of dengue are detected, the population as a whole may have already been primed with prior DENV infection.

The frequency of inapparent infections is extremely variable year to year, the risk factors poorly understood, and the terminology not standardized. Subclinical, inapparent, and asymptomatic infections are often used as synonyms, and the use of paucisymptomatic is used to designate a DENV infection with few symptoms. We will use subclinical and inapparent to denote infections with insufficient symptoms to be detected by the research or national surveillance program and/or to incite the infected individual to consult, but for which there is evidence, either by seroconversion or detection of virus, that the individual was infected with DENV. Asymptomatic infections will be used when there are no symptoms at all reported by the infected individual during an active infection, whether inferred by seroconversion or serology.

We review the literature on the extent of inapparent DENV infections, identify associated risk factors, and highlight several important lacunae that need to be addressed to assess the extent of the epidemiological importance of inapparent infections. We combine a PubMed literature search approach with review of articles cited within PubMed hits, plus a review of the classical pre-PubMed dengue literature. The search strategy was dengue + one of the following: inapparent, asymptomtic, subclinical. This search (27 January 2014) yielded 28, 151, and 34 articles, respectively. Acceptance criteria for selection were: (i) definition of symptom classification, (ii) ascertainment of symptoms and recent/concurrent viral infection at an individual level, and (iii) quantification of the number of inapparent infections. Of the retrieved PubMed articles, 33 publications fulfilled the acceptance criteria (19-51). An additional 14 articles cited within the above fulfilled acceptance criteria (52-65). One further recent article was known to the authors (66). A short description of each study is presented in the Supplementary Material and in Table 1. Below, we highlight features pertinent to dengue epidemiology that these studies elucidate.

\section{RETROSPECTIVE AND OUTBREAK STUDIES}

There were 12 retrospective or outbreak studies with measures of seropositivity and subjective recollection of fever and/or dengueassociated symptoms (Australia 1, British Virgin Islands 1, Colombia 1, Cuba 2, Puerto Rico 2, Brazil 2, South Pacific 1, Singapore 1, and Taiwan 1) (19-25, 53-57). In Cuba, the inapparent rate during the 1981 DENV-2 epidemic was estimated to be $71 \%$ in whites and $88 \%$ in blacks; the infections were considered likely to be $2^{\circ}$, as $45 \%$ of the population was thought to have seroconverted during the 1977 DENV-1 epidemic (54). During the 1997 Cuban DENV-2 epidemic, all $2^{\circ}$ infections were clinically overt, but only $3-6 \%$ of $1^{\circ}$ infections were apparent (55). In the Brazilian studies, inapparent rates were 27 and $53 \%$ in $1^{\circ}$ infections vs. 37 and $39 \%$ in $2^{\circ}$ infections $(22,23)$. In Colombia, repeated cross-sectional studies were carried out over a period of 17 months; 259 of 3,189 individuals showed clinical signs of viral infection and/or antiDENV IgM antibodies; $86 \%$ were inapparent (24). In the Puerto Rican studies, where infections were majoritarily $1^{\circ}$, inapparent rates were 53 and $43 \%(56,57)$. The Singapore and South Pacific studies were carried out during the epidemic period, and inapparent rates of 78 and $60 \%$ were reported, respectively $(25,53)$. The Australian study was performed in 1995 to address the 1993 DENV epidemic; only $11 \%$ of infections were considered to be inapparent (19). Longer-term recollection of $1^{\circ}$ infections in individuals hospitalized in Taiwan with $2^{\circ}$ infections suggested that $80 \%$ of $1^{\circ}$ infections had been inapparent (21). Finally, returning US volunteers from the British Virgin Islands in a community with a suspected dengue case revealed that all DENV IgM-positive individuals had recollection of symptoms (20).

\section{NON-RESIDENTS (EXPATS, MILITARY, AND TRAVELERS)}

Nine prospective studies were identified involving expats, travelers, or military personnel staying in dengue-endemic areas (Haiti 1, Singapore 1, Somalia 1, Thailand 2, various 4) (48-51, 61-65). Seroconversion rates were low, yielding relatively few infections in any study. In the majority of studies, symptomatic infections referred to the occurrence of any dengue-like symptom. Sharp et al. (62) and Cobelens et al. (49) defined a symptomatic infection as fever plus any other symptom. Baaten et al. (50) obtained objective measure of fever or any other symptoms for defining symptomatic DENV infections (50). For the majority of individuals, the infection was considered to be their first, and the inapparent rate ranged from 0 to $100 \%$. The majority (80-100\%) of Americans (61) and Japanese (48) in Thailand had symptoms, whereas no Australian travelers to Asia reported symptoms (51). Sixty to $80 \%$ of Dutch travelers (world-wide) reported no symptoms $(49,50)$, whereas $50 \%$ of Israeli travelers had symptoms (63). Over $90 \%$ of Chinese workers experienced symptoms in Singapore (64), 85\% of American military personnel had symptoms in Somalia (62), and all seven missionaries who were seropositive for DENV returning from Haiti reported dengue-like symptoms (65). 
Table 1 | Prospective studies addressing the inapparent rate

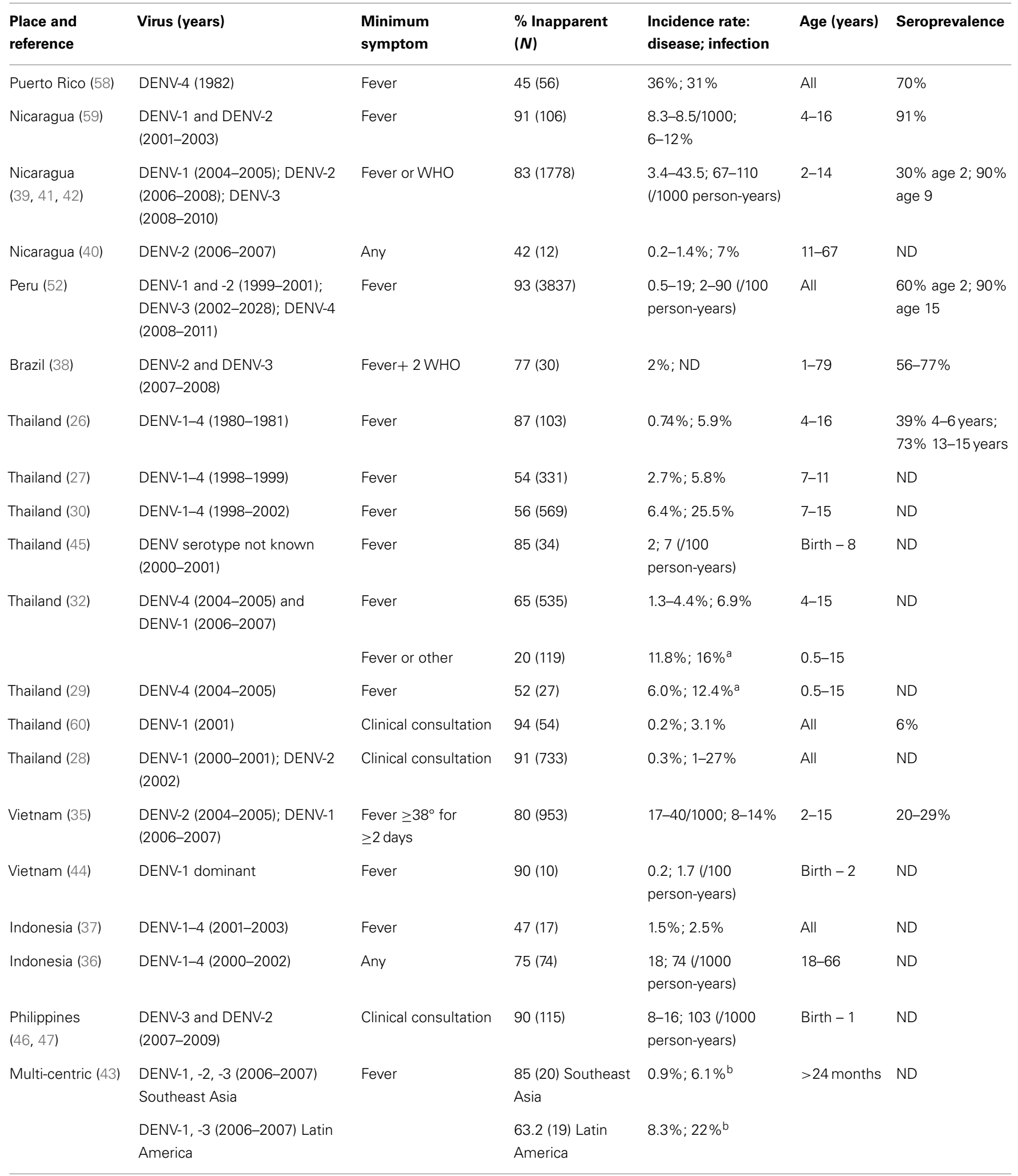

andicates positive index clusters only; cluster contacts followed for 15 days or ${ }^{b} 7$ days. 


\section{BIRTH COHORTS - MATERNAL ANTIBODY STUDIES}

Four birth cohort studies addressed the potentially deleterious effects of maternal antibody for outcome of DENV infection in infants (Philippines 2, Vietnam 1, Thailand 1) (44-47). The occurrence of severe disease in infants following their first infection was noted by Halstead and colleagues and contributed to the development of the theory of antibody-dependent enhancement (ADE); antibodies from a first infection are insufficient to neutralize virus from a second infection of a different serotype and actually increase virus internalization in $\mathrm{Fc} \gamma$ receptor-bearing target cells and hence viremia (67). In infants, following a period of protection by maternally acquired anti-DENV antibodies, catabolism of these antibodies was hypothesized to decrease the titer of maternally acquired antibodies to enhancing levels and thus lead to the high incidence of severe dengue disease observed in infants (68). The birth cohort studies did not confirm the ADE hypothesis, although samples sizes were small. The inapparent DENV infection rate ranged from 75 to $90 \%$.

\section{PROSPECTIVE STUDIES}

Twenty-three published papers describe analyses of prospective studies carried out in Southeast Asia (Thailand 10, Vietnam 1, Indonesia 2) $(26-37,60)$ and the Americas (Brazil 1, Nicaragua 5, Peru 2, Puerto Rico 1) $(38-42,52,58,59,66)$ and one multicenter study covering Vietnam, Cambodia, French Guiana, and Brazil (43). The Thai studies occurred in one of three sites (Bangkok, Chang Mai, or Kamphaeng Phet); the Nicaragua, Peru, and Indonesia studies occurred in Managua, Iquitos, and Jakarta, respectively. The studies used one or more of several protocols: community-based cohort with paired healthy samples and laboratory work-up of suspected dengue cases/undifferentiated febrile illnesses, follow-up of school-based absenteeism, and index cluster analysis. Anti-DENV antibodies were detected using rapid diagnostic kits, in-house ELISA assays, hemagglutination inhibition assay, and/or neutralizing antibody tests. The age group sampled varied considerably, as did the seroprevalence and force of infection. Notably, although the majority of studies focused on children or the general community, one of the Indonesian studies targeted an adult cohort (36). The classification of a symptomatic DENV infection varied from the presence of any symptom, to just fever or fever plus two additional dengue-associated symptoms according to the WHO case definition. The inapparent DENV infection rate ranged from 20 to $97 \%$; the weighted mean inapparent rates of cluster and cohort studies were 37 and $76 \%$ respectively. Mean inapparent rates in cohort studies were $77.1 \%$ in the Americas and $74.4 \%$ in Asia.

\section{EXPERIMENTAL INOCULATIONS (Pre-1960s)}

The experimental infection studies in the first half of the twentieth century provide the foundations of our current knowledge of dengue $(69,70)$. Siler et al. (69) conducted a series of induced infection experiments in military personnel using infected mosquitoes. Of 47 subjects, four individuals remained refractory to infection (or were asymptomatic) and two had very mild symptoms. The inclusion criteria aimed to recruit individuals who were naïve to dengue, but it could not be ruled out that some individuals had been previously exposed to DENV. Thus, assuming no immunity, the inapparent rate was at most $13 \%(6 / 47)$.

Simmons et al. (70) gave detailed accounts of the course and outcome of infection using mosquito-induced infections in American military personnel, residents of the Philippines, monkeys, and other animals (70). All 81 infections induced using competent species of mosquitoes (A. aegypti, A. albopictus) after an appropriate extrinsic incubation period ( $>9$ days) yielded DF; only $13.6 \%$ were classified as mild (undefined). The extent of asymptomatic or even inapparent infections was clearly very low in American military personnel with no likely previous exposure to dengue. Adult Philippine individuals living in endemic zones for dengue proved immune, whereas those from non-endemic areas proved susceptible and were symptomatic following DENV infection. Successful experimental infections without symptoms in naïve Macaque monkeys were achieved, as demonstrated through onward transmission to mosquitoes. Although such onward transmission studies were not carried out in purportedly unsuccessful DENV-induced infections in humans, the authors state "In addition, it is quite probable that mild unrecognizable infections may occur in many adults, as has been proved possible in monkeys, and that virus can be transmitted from these apparently symptomless cases of dengue."

\section{POTENTIAL EXPLANATIONS FOR DIFFERENCES IN OBSERVED INAPPARENT RATES DETECTION METHODOLOGY}

Retrospective surveys involving questionnaires of perceived symptoms are open to perception bias as well as the non-specificity of dengue symptoms. Prospective studies use varying definitions of a symptomatic dengue episode and different protocols for case detection that generate considerable variation in inapparent infection rates. This is particularly well demonstrated by two alternative protocols implemented in the same population: the index cluster approach revealed that many inapparent infections, as defined by school absenteeism and passive case detection, had fever or other symptoms (32). In addition to the increased case detection sensitivity of the index cluster approach, such an approach may also suffer from ascertainment bias: viruses responsible for index cases identified by clinical presentation may be more pathogenic and thus lead to increased symptomatic infections in the clusters than would occur in the general population. However, symptomatic cases in clusters were found to be milder than those in the cohort study (33).

\section{INFLUENCE OF HUMAN GENETICS}

A broad overview of global incidence of disease attributable to dengue suggests that disease severity is greater in Southeast Asia than in the Americas and that severe dengue is infrequent in Africa (71). One major confounding factor is separating geography and the environment from ethnicity. However, the dengue epidemics in Cuba have given support to the hypothesis that individuals of African ethnicity are less susceptible to disease than white Caucasians (54). There is increasing evidence from candidate gene and genome-wide studies that human genetics play a role in the outcome of infection (72-74). Only one study, however, has attempted to assess the impact of human genetics on inapparent outcome 
of infection. A polymorphism in the Fc $\gamma$ RIIA was found to be associated with inapparent infection vs. DF or DHF in the Cuban population (75). In light of the epidemiological observations on the global variation in the incidence of DENV infection and severe disease, it seems likely that at least some of the observed variation in the inapparent rate is attributable to human genetics.

\section{PRIMARY VS. SECONDARY VS. POST-SECONDARY INFECTIONS}

Secondary infections are considered to result in more severe outcome of infection, due to the phenomenon of ADE and/or crossreactive $\mathrm{T}$ cells (67). Very little, however, is known specifically about the impact of previous exposure to two serotypes on the outcome of infection with a third serotype. A cohort study in Brazil found that there were significantly more inapparent infections in $1^{\circ}$ as compared to $2^{\circ}$ infections (22). Olkowski et al. (66) found that in Peru there was a reduction in symptomatic outcome in post-secondary infections compared with $1^{\circ}$ and $2^{\circ}$ infections as defined by pre-infection serological profile; $93 \%$ reduction in symptomatic outcome for DENV-3 and a 64\% reduction in disease outcome for DENV-4 (66). However, Montoya et al. (42) found no differences in inapparent infection rates in first, second, third, or even post-secondary infections in Nicaragua (42). Several studies measuring the inapparent rate also evaluated whether the observed infection was $1^{\circ}$ or $2^{\circ}(22,23,26,29,32,38,39,42$, $43,52,59)$. A mixed model logistic univariate regression revealed that although there were significant differences in inapparent rate among studies, there was no significant difference within study site between the inapparent rate in $1^{\circ}$ and $2^{\circ}$ infections (Wald's $\chi_{1}^{2}=0.27, P=0.61$ ) (Figure 1). Too few studies have been able to address post-secondary (third or fourth) infections and infection outcome for any meta-analysis to be performed.

\section{SHORT-TERM CROSS-PROTECTIVE IMMUNITY}

Sabin set the foundations for our current appreciation of acquired immunity to dengue and the extent of cross-immunity (76). Three important results arising from these early studies are of pertinence here: (i) there exists a minimum infective dose, which could lead to no symptoms but partial immunity; (ii) immunity to a recent previous infection alters the outcome of a subsequent infection; and (iii) virus attenuated via mouse passage yields symptomless infections that are transmissible to mosquitoes, albeit poorly so. For cross-immunity, active immune protection was achieved for up to 2 months, slight malaise/fever occurred in $2^{\circ}$ infections 2-3 months later, and even after 9 months, dengue episodes were milder. DENV infection and onward transmission to mosquitoes was demonstrated in $2^{\circ}$ infections at $2-3$ months and 9 months post $-1^{\circ}$ infection. Recent statistical and theoretical modeling approaches lend support to Sabin's demonstration that there exists cross-serotype non-sterilizing immunity resulting in milder clinical symptoms that may last for up to 2 years (77-79).

Endy et al. (30) first noted a significant impact of the previous year's dengue incidence on the inapparent rate; a high incidence the previous year increased the current year's inapparent rate. This was proposed to be a result of heterotypic cross-immunity, as described above. A plot of the inapparent rate against previous dengue incidence reported in the longitudinal cohorts with sufficient data (Nicaragua, Peru, Thailand, and Vietnam) (30, 35, 39, $41,42,52$ ), all show the same positive relationship between the incidence of infection the previous year and the inapparent rate in the current year (Figure 2). However, the strength of the relationship seems proportional to the seroprevalence. In Nicaragua and Peru, the seroprevalence in the population was high, with most children having been exposed to at least one serotype by 10 years

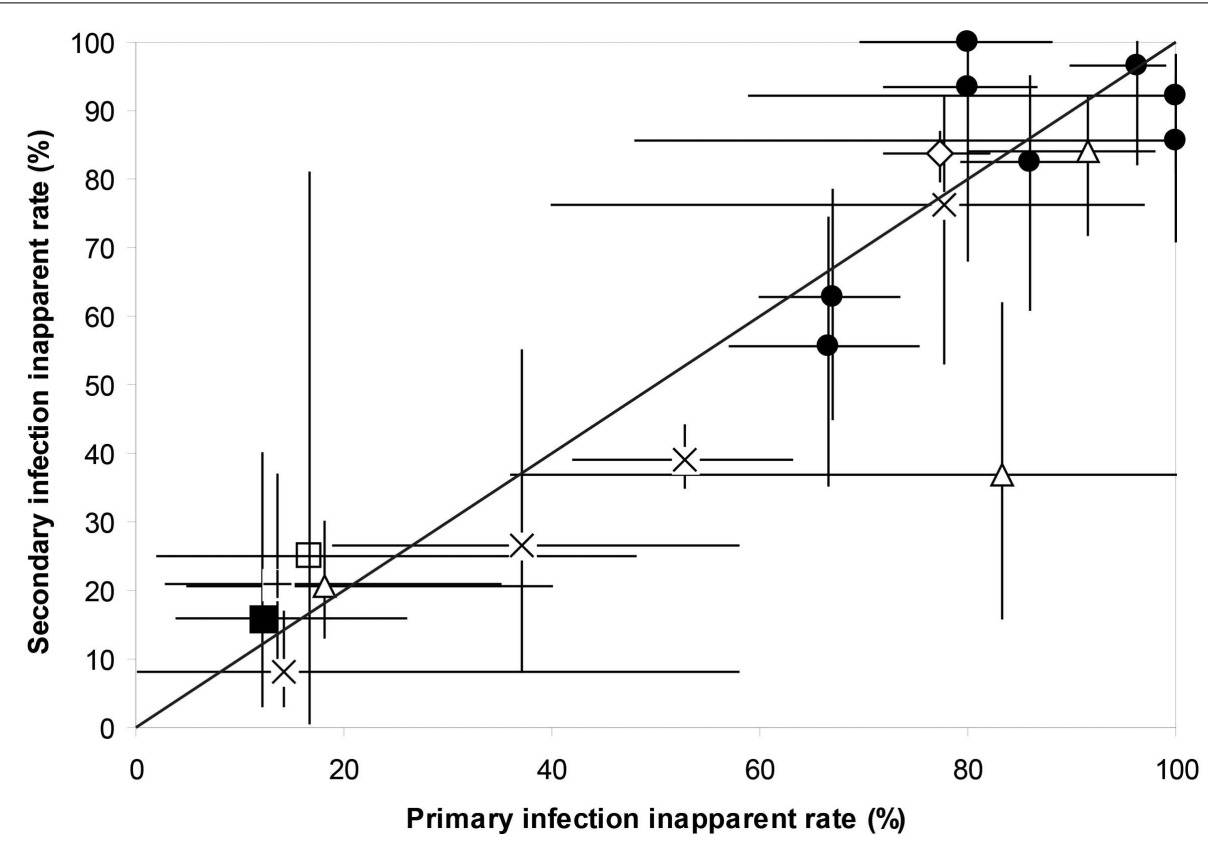

FIGURE 1 | The inapparent rate of primary and secondary DENV infections within the same study site for Nicaragua $(39,41,42,59)$, Thailand (26, 29, 32), Brazil $(22,23,38)$, Peru (52), French Guiana, Cambodia, and Vietnam (43). Shown are means and $95 \%$ binomial confidence intervals. Superimposed is the line of equality where the inapparent rate of $2^{\circ}$ infections equals that of $1^{\circ}$ infections. - Nicaragua, - Vietnam, + Cambodia, $\times$ Brazil, $\diamond$ Peru, $\square$ French Guiana, $\triangle$ Thailand. 

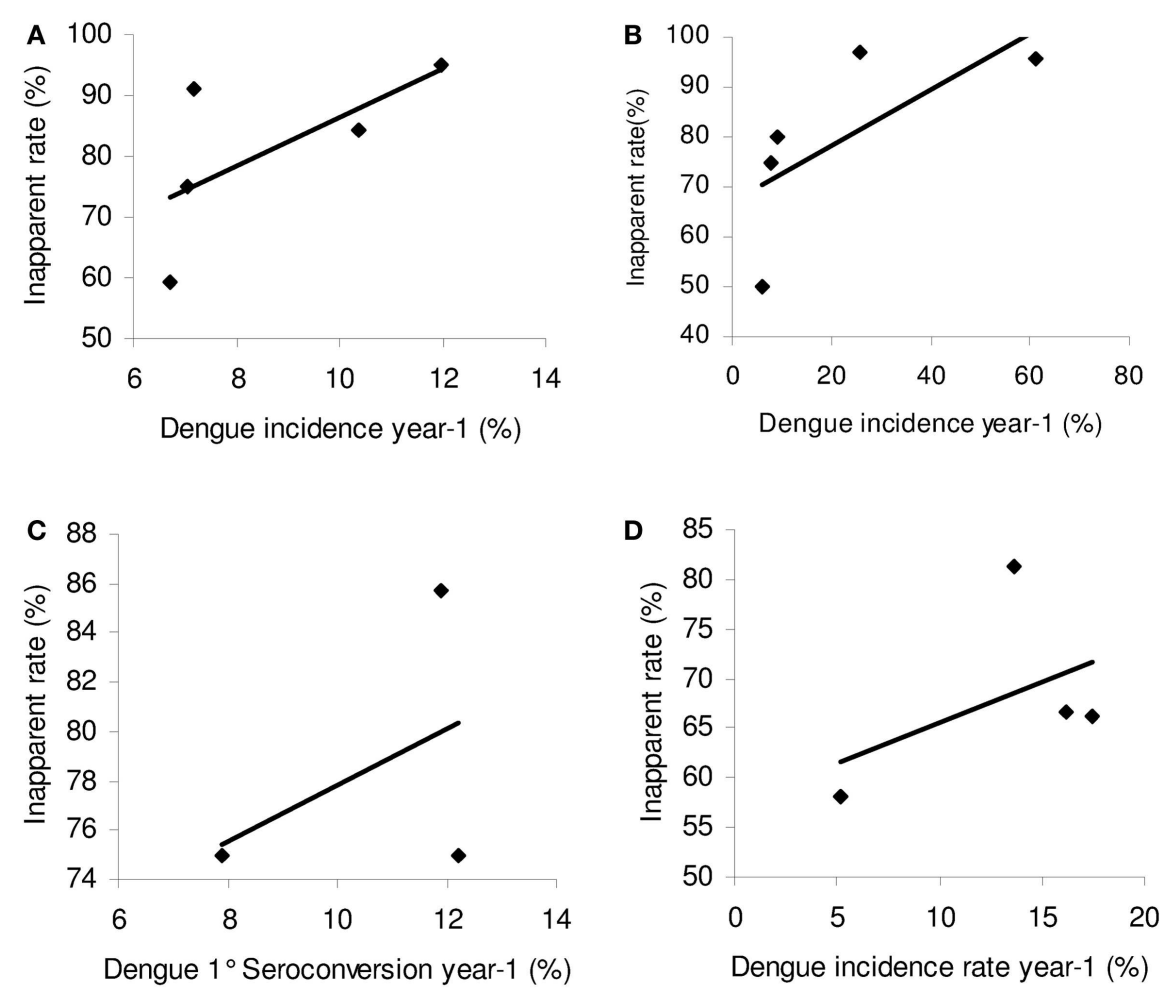

FIGURE 2 |The relationship between the inapparent infection rate and DENV infection intensity the previous year. Linear trend lines were fitted. (A) Nicaragua $(39,41) R^{2}=0.43$; (B) Peru (52) $R^{2}=0.477$. (C) Vietnam (35) $R^{2}=0.20$; (D) Thailand (30) $R^{2}=0.21$.

of age. In Vietnam, by contrast, the seroprevalence was lower for the same age group (35). The correlation of the incidence of infection the previous year and the inapparent rate in the current year are strongest for areas of higher seroprevalence and thus where the majority of new infections are $2^{\circ}$. It is notable that the positive relationship for inapparent rate and previous year DENV incidence of infection was significantly stronger when considering incidence of disease the previous year $\left(R^{2}=0.76\right)$ rather than infection $\left(R^{2}=0.2\right)$ in the Vietnam cohort. This raises the question of whether the acquired immune response is stronger when infection is accompanied by disease, rather than being asymptomatic; this has previously been observed in Japanese Encephalitis (quoted in Barnes and Rosen) (53).

Of key importance is to ascertain whether the inapparent rate is indeed driven by heterotypic immunity. The Nicaraguan Pediatric Dengue Cohort Study throws some light on the question, differentiating $1^{\circ}$ from $2^{\circ}$ infections (39). A reduced symptomatology in the outcome of infection through heterotypic immunity would only apply to $2^{\circ}$ infections. The fluctuations in the interannual inapparent rate in $2^{\circ}$ infections oscillated inversely with the previous years' incidence rate, ranging from 67 to $97 \%$ and significantly so with non-overlapping $95 \%$ binomial confidence intervals (CIs) (calculated as inapparent/total infections) (Figure 3B). By contrast, although the same oscillating inter-annual pattern was observable in $1^{\circ}$ infections, for which cross-protective immunity is not relevant, the fluctuations were dampened, ranging from 82 to $92 \%$, with overlapping 95\% CIs (Figure 3A). This gives credence to the hypothesis that short-term cross-protective immunity plays a significant role in determining infection outcome in $2^{\circ}$ infections.

More recently, several studies have analyzed the importance of the time interval between successive DENV infections on the outcome of infection in first, second, and post- $2^{\circ}$ infections. In the Nicaragua cohort, Montoya et al. (42) found that the time interval between successive first and second infections leading to an inapparent second infection outcome was significantly shorter ( 1.8 years) than that leading to a symptomatic infection outcome (2.6 years) (42). There was no impact of time interval for post$2^{\circ}$ infections. In Thai cohorts, Anderson et al. (34) found similar results; there was a higher probability of an infection being inapparent in $2^{\circ}$ infections if occurring within 1.4 years of a previous (thus $1^{\circ}$ ) infection; the time interval between infections leading to DF or DHF was longer, at 1.9 and 2.6 years respectively, although the number of DHF was small (34). Again there was no difference for post- $2^{\circ}$ infections.

\section{IMPACT OF THE CURRENT YEAR'S INCIDENCE}

Endy et al. (30) also noted a significant negative impact of the current year's dengue incidence on the inapparent rate; a high concurrent incidence reduced the inapparent infection rate (30). This relationship was confirmed in the same cohort $\left(R^{2}=1\right)(32)$, but to a much lesser extent in both the Nicaraguan and Vietnamese studies $\left(R^{2}=0.12\right.$ and 0.23 , respectively) $(35,39)$. There was no relationship in the Peruvian study $\left(R^{2}=0.07\right)$ (52). Careful studies 

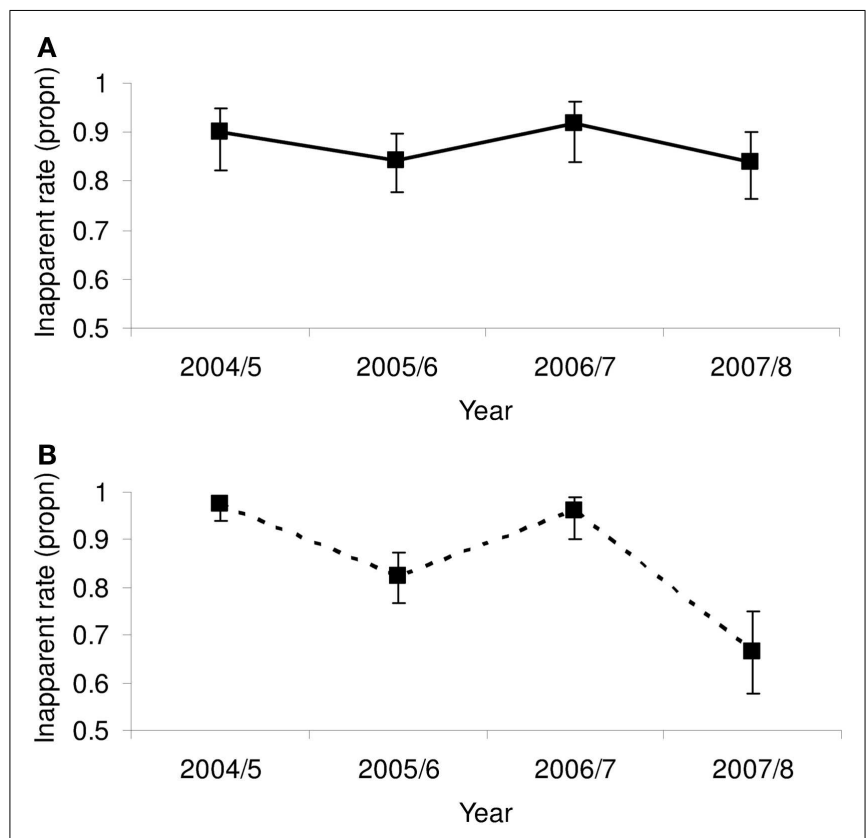

FIGURE 3 |The proportion of (A) $1^{\circ}$ and (B) $2^{\circ}$ infections in the Nicaraguan Pediatric Dengue Cohort Study (39) that was inapparent. Shown are the proportions and the 95\% binomial confidence intervals.

taking into account the force of infection in relation to inapparent and symptomatic infection are needed.

The interplay between short-term cross-protective immunity and spread of a novel serotype will lead to inapparent rates that will depend on the historical prevalence of dengue (thus, the extent of $2^{\circ}$ infections), the recent incidence of dengue (cross-protection), and the nature of the virus itself. By example, in the Nicaraguan cohort, the expansion of DENV-2 in 2005 (increasing from $20 \%$ of infections to 53\%) was accompanied by an increase in transmission intensity (8.6-11.1\% incidence) and increase in symptomatic outcome, particularly for $2^{\circ}$ infections (3-25\%) (39). This suggests a classic reaction to a new serotype in a background primed by other serotypes. The following year, transmission intensity dropped (from 11.1 to $5.8 \%$ ), there was an increase in the predominance of DENV-2 (90\% of all infections), and a decrease in rate of symptomatic infections; this decrease was most dramatic for $2^{\circ}$ infections ( 25 to $4 \%$ ), suggesting an important influence of crossprotective immunity. Then, transmission intensity increased with a concomitant rise in disease severity in both $1^{\circ}$ and $2^{\circ}$ infections. The rise in disease severity despite no change in serotype would suggest that the virus had evolved. Indeed, there was a clade change in 2006 (from DENV-2 clade 1 to clade 2B), which was associated with increased severity in the cohort and which could have contributed to the final increase in severity of infection outcome (80).

Morrison et al. (52) proposed a three-step chronology for the invasion of a novel serotype: amplification, replacement, and epidemic (52). Implicitly underlying this chronology is the notion of viral adaptation to its novel environment in competitive circumstances. Viral evolution may also contribute to the rise in the inapparent rate following the epidemic phase. Abortive dengue epidemics, where the incidence of disease is low, have been noted previously, and islands in the South Pacific have escaped severe outbreaks occurring in their neighbors $(53,81)$.

\section{VIRAL GENETICS}

The importance of viral genetics in determining the outcome of infection has been suggested in the context of $1^{\circ}$ vs. $2^{\circ}$ infections (82), severe primary epidemics in naïve populations $(53,81)$, molecular variants yielding high replication rates in the laboratory (83), DENV serotype, genotype, and clade, sequential order of serotypes in infections (84), and interaction with pre-existing serotypespecific immunity $(80,85)$. However, there is no consistent pattern. Whilst confounding factors influence the disease severity of an epidemic, the genetic diversity of the viruses likely plays an important role. As with all arboviruses, the RNA-dependent RNA polymerase's lack of proofreading activity coupled with the large virus population sizes lead to the constant generation of variants. This means that RNA viruses generally circulate as dynamic mutant networks (86). Recent studies reveal that DENV exist as heterogeneous populations in patients and mosquito vectors (87-93), but the significance of this is unclear. Coupled to the selective forces in both host and vector, these features would enable the circulating viral population to change significantly even during the course of a single epidemic. Indeed, the proportion of severe cases has been reported to increase toward the end of an outbreak (94-96). Endy et al. (27) also noted that symptomatic cases extended later into the season than inapparent infections (27). DENV populations may also rapidly change because of periodic selective sweeps and by intra-serotypic recombination $(97,98)$, though this latter remains contentious. DENV infection leads to a spectrum of outcome severity from inapparent to mild or severe disease; small changes in viral genetics could lead to significant changes in infection outcome. However, despite increasing evidence for a role of viral genetics in the outcome of infection, to date we do not know the extent to which the observed variation in the inapparent rate is influenced by viral diversity and evolution.

Genetic variation has been associated with differences in virus transmission efficiency $(99,100)$. Viral adaptation during its invasion phase may improve transmission capacity to mosquitoes responsible for an epidemic and/or result in strains that are responsible for more severe cases toward the end of the epidemic. Infectiousness to mosquito increases with viremia and although hospitalized cases have higher viremia, symptomatic but ambulatory cases infected mosquitoes equally well (101). Currently, we have no knowledge about the comparative transmissibility of inapparent infections, a crucial element that needs to be addressed.

\section{CONCLUSION AND IMPLICATIONS}

Establishing risk factors and the extent to which DENV infections are inapparent is important not only for assessing whether there will be a silent invasion of DENV into hitherto unaffected areas but also for improving our understanding of dengue epidemiology and infection severity. The epidemiological evidence to date suggests that whilst the majority of infections are inapparent in endemic settings, there are recognizable patterns that are consistent with an important role for short-term heterotypic non-sterilizing immunity. However, similar inter-annual fluctuations in the inapparent rate in $1^{\circ}$ infections require additional explanations, potentially suggesting a role for viral evolution. One intriguing avenue of 
research is the extent to which heterotypic immunity promotes viral diversification. Likewise, it would be interesting to assess how human genetics impacts upon infection outcome.

Extrapolating from endemic settings to an invasion scenario may not be applicable, especially given the significant role seemingly played by the immune response in $2^{\circ}$ infections, whether enhancing or protective. Retrospective serological surveys in recent virgin soil epidemics, for example, in Madeira and Cape Verde, would provide invaluable information on the extent of inapparent infections under such scenarios and give a better idea of what to expect under invasion and hence how best to implement surveillance and control efforts.

Finally, an appreciation of inapparent DENV infections is important for both interpretation of vaccine trials and vaccine uptake. It has been suggested that, in the light of the high incidence of inapparent DENV infections, vaccine trials should consider other measures of vaccine efficacy in addition to occurrence of clinically apparent infections, i.e., to consider efficacy against infection and not just disease (102). Moreover, pre-existing immunity from prior symptomatic and inapparent DENV infections will likely affect the type of immunity induced by tetravalent vaccines (i.e., homotypic vs. heterotypic), and this needs to be considered as well. Lastly, successful vaccination should reduce the large reservoir of inapparent infections that are likely capable of onwardly transmitting the virus, thus further reducing DENV transmission.

\section{AUTHOR CONTRIBUTIONS}

All authors contributed equally to the manuscript. Specifically, Richard Paul and Eva Harris conceived the study. All authors participated in the data acquisition and preliminary writing. Etienne Simon-Loriere created the graphics and Richard Paul carried out the statistical analyses. Richard Paul and Eva Harris wrote the final version and all authors read, corrected, and approved the final version.

\section{ACKNOWLEDGMENTS}

Funding: Agence Nationale de la Recherche, France (ANR 10CEPL-004-AEDESS to Richard Paul) and the research leading to these results has received funding from the European Commission Seventh Framework Programme (FP7/2007-2013) for the DENFREE project under Grant Agreement no. 282378. Research reported in this publication was supported by the National Institute of Allergy and Infectious Diseases of the National Institutes of Health under Award Number R01AI099631. The content is solely the responsibility of the authors and does not necessarily represent the official views of the National Institutes of Health. The funding source had no role in study design, data collection, data analysis, data interpretation, or writing of the report. The corresponding authors had full access to all the data in the study and had final responsibility for the decision to submit for publication.

\section{SUPPLEMENTARY MATERIAL}

The Supplementary Material for this article can be found online at http://www.frontiersin.org/Journal/10.3389/fimmu.2014.00280/ abstract

\section{REFERENCES}

1. Gubler D, Kuno G. Dengue and Dengue Hemorrhagic Fever. Wallingford: CAB International (1997). 496 p.
2. Lambrechts L, Scott TW, Gubler DJ. Consequences of the expanding global distribution of Aedes albopictus for dengue virus transmission. PLoS Negl Trop Dis (2010) 4:e646. doi:10.1371/journal.pntd.0000646

3. Halstead SB. Dengue. Lancet (2007) 370:1644-52. doi:10.1016/S01406736(07)61687-0

4. WHO. Dengue and Dengue Hemorrhagic Fever, Fact Sheet 117. (2009). Available from: http://www.who.int/mediacentre/factsheets/fs117/en/

5. Normile D. Tropical medicine. Surprising new dengue virus throws a spanner in disease control efforts. Science (2013) 342:415. doi:10.1126/science.342. 6157.415

6. Halstead SB. Is there an inapparent dengue explosion? Lancet (1999) 353:1100-1. doi:10.1016/S0140-6736(05)76461-8

7. Bhatt S, Gething P, Brady O, Messina J, Farlow A, Moyes C, et al. The global distribution and burden of dengue. Nature (2013) 496:504-7. doi:10.1038/ nature 12060

8. Gubler DJ. Epidemic dengue/dengue hemorrhagic fever as a public health, social and economic problem in the 21st century. Trends Microbiol (2002) 10:100-3. doi:10.1016/S0966-842X(01)02288-0

9. Chen LH, Wilson ME. The role of the traveler in emerging infections and magnitude of travel. Med Clin North Am (2008) 92:1409-32. doi:10.1016/j.mcna. 2008.07.005

10. Hales S, de Wet N, Maindonald J, Woodward A. Potential effect of population and climate changes on global distribution of dengue fever: an empirical model. Lancet (2002) 360:830-4. doi:10.1016/S0140-6736(02)09964-6

11. Thai KT, Anders KL. The role of climate variability and change in the transmission dynamics and geographic distribution of dengue. Exp Biol Med (2011) 236:944-54. doi:10.1258/ebm.2011.010402

12. La Ruche G, Souarès $Y$, Armengaud A, Peloux-Petiot F, Delaunay P, Desprès $P$, et al. First two autochthonous dengue virus infections in metropolitan France, September 2010. Euro Surveill (2010) 15:ii19676.

13. Alves MJ, Fernandes PL, Amaro F, Osório H, Luz T, Parreira P, et al. Clinical presentation and laboratory findings for the first autochthonous cases of dengue fever in Madeira island, Portugal, October 2012. Euro Surveill (2013) 18:20398.

14. Effler PV, Pang L, Kitsutani P, Vorndam V, Nakata M, Ayers T, et al. Dengue fever, Hawaii, 2001-2002. Emerg Infect Dis (2005) 11:742-9. doi:10.3201/eid1105. 1063

15. Murray KO, Rodriguez LF, Herrington E, Kharat V, Vasilakis N, Walker C, et al. Identification of dengue fever cases in Houston, Texas, with evidence of autochthonous transmission between 2003 and 2005. Vector Borne Zoonotic Dis (2013) 13:835-45. doi:10.1089/vbz.2013.1413

16. Guzman MG, Halstead SB, Artsob H, Buchy P, Farrar J, Gubler DJ, et al. Dengue: a continuing global threat. Nat Rev Microbiol (2010) 8:S7-16. doi: $10.1038 /$ nrmicro 2460

17. Vaughn DW. Invited commentary: dengue lessons from Cuba. Am J Epidemiol (2000) 152:800-3. doi:10.1093/aje/152.9.800

18. Guzmán MG, Kourí G, Valdés L, Bravo J, Vázquez S, Halstead SB. Enhanced severity of secondary dengue-2 infections: death rates in 1981 and 1997 Cuban outbreaks. Rev Panam Salud Publica (2002) 11:223-7. doi:10.1590/S102049892002000400003

19. McBride WJ, Mullner H, LaBrooy JT, Wronski I. The 1993 dengue 2 epidemic in Charters Towers, North Queensland: clinical features and public health impact. Epidemiol Infect (1998) 121:151-6. doi:10.1017/S0950268898001058

20. Lyerla R, Rigau-Pérez JG, Vorndam AV, Reiter P, George AM, Potter IM, et al. A dengue outbreak among camp participants in a Caribbean island, 1995. J Travel Med (2000) 7:59-63. doi:10.2310/7060.2000.00022

21. Yeh WT, Chen RF, Wang L, Liu JW, Shaio MF, Yang KD. Implications of previous subclinical dengue infection but not virus load in dengue hemorrhagic fever. FEMS Immunol Med Microbiol (2006) 48:84-90. doi:10.1111/j.1574695X.2006.00127.x

22. Vasconcelos PF, Lima JW, da Rosa AP, Timbó MJ, da Rosa ES, Lima HR, et al. Dengue epidemic in Fortaleza, Ceará: randomized seroepidemiologic survey. Rev Saude Publica (1998) 32:447-54. doi:10.1590/S0034-89101998000500007

23. Rodrigues EM, Dal-Fabbro AL, Salomao R, Ferreira IB, Rocco IM, Fonseca BA. Epidemiology of dengue infection in Ribeirão Preto, SP, Brazil. Rev Saude Publica (2002) 36:160-5. doi:10.1590/S0034-89102002000200007

24. Méndez F, Barreto M, Arias JF, Rengifo G, Muñoz J, Burbano ME, et al. Human and mosquito infections by dengue viruses during and after epidemics in a dengue-endemic region of Colombia. Am J Trop Med Hyg (2006) 74:678-83. 
25. Yap G, Li C, Mutalib A, Lai YL, Ng LC. High rates of inapparent dengue in older adults in Singapore. Am J Trop Med Hyg (2013) 88:1065-9. doi:10.4269/ajtmh. 12-0150

26. Burke DS, Nisalak A, Johnson DE, Scott RM. A prospective study of dengue infections in Bangkok. Am J Trop Med Hyg (1988) 38:172-80.

27. Endy TP, Chunsuttiwat S, Nisalak A, Libraty DH, Green S, Rothman AL, et al. Epidemiology of inapparent and symptomatic acute dengue virus infection: a prospective study of primary school children in Kamphaeng Phet, Thailand. Am J Epidemiol (2002) 156:40-51. doi:10.1093/aje/kwf005

28. Vanwambeke SO, van Benthem BH, Khantikul N, Burghoorn-Maas C, Panart $\mathrm{K}$, Oskam L, et al. Multi-level analyses of spatial and temporal determinants for dengue infection. Int J Health Geogr (2006) 5:5. doi:10.1186/1476-072X-5-5

29. Mammen MP, Pimgate C, Koenraadt CJ, Rothman AL, Aldstadt J, Nisalak A, et al. Spatial and temporal clustering of dengue virus transmission in Thai villages. PLoS Med (2008) 5:e205. doi:10.1371/journal.pmed.0050205

30. Endy TP, Anderson KB, Nisalak A, Yoon IK, Green S, Rothman AL, et al. Determinants of inapparent and symptomatic dengue infection in a prospective study of primary school children in Kamphaeng Phet, Thailand. PLoS Negl Trop Dis (2011) 5:e975. doi:10.1371/journal.pntd.0000975

31. Anderson KB, Gibbons RV, Thomas SJ, Rothman AL, Nisalak A, Berkelman $\mathrm{RL}$, et al. Preexisting Japanese encephalitis virus neutralizing antibodies and increased symptomatic dengue illness in a school-based cohort in Thailand. PLoS Negl Trop Dis (2011) 5:e1311. doi:10.1371/journal.pntd.0001311

32. Yoon IK, Rothman AL, Tannitisupawong D, Srikiatkhachorn A, Jarman RG, Aldstadt J, et al. Underrecognized mildly symptomatic viremic dengue virus infections in rural Thai schools and villages. J Infect Dis (2012) 206:389-98. doi:10.1093/infdis/jis357

33. Yoon IK, Srikiatkhachorn A, Hermann L, Buddhari D, Scott TW, Jarman RG, et al. Characteristics of mild dengue virus infection in Thai children. Am J Trop Med Hyg (2013) 89:1081-7. doi:10.4269/ajtmh.13-0424

34. Anderson KB, Gibbons RV, Cummings DA, Nisalak A, Green S, Libraty DH, et al. A shorter time interval between first and second dengue infections is associated with protection from clinical illness in a school-based cohort in Thailand. J Infect Dis (2014) 209:360-8. doi:10.1093/infdis/jit436

35. Tien NT, Luxemburger C, Toan NT, Pollissard-Gadroy L, Huong VT, Van Be $\mathrm{P}$, et al. A prospective cohort study of dengue infection in schoolchildren in Long Xuyen, Vietnam. Trans R Soc Trop Med Hyg (2010) 104:592-600. doi:10.1016/j.trstmh.2010.06.003

36. Porter KR, Beckett CG, Kosasih H, Tan RI, Alisjahbana B, Rudiman PI, et al. Epidemiology of dengue and dengue hemorrhagic fever in a cohort of adults living in Bandung, West Java, Indonesia. Am J Trop Med Hyg (2005) 72:60-6.

37. Beckett CG, Kosasih H, Faisal I, Nurhayati, Tan R, Widjaja S, et al. Early detection of dengue infections using cluster sampling around index cases. Am J Trop Med Hyg (2005) 72:777-82.

38. Honório NA, Nogueira RM, Codeço CT, Carvalho MS, Cruz OG, Magalhães Mde A, et al. Spatial evaluation and modeling of Dengue seroprevalence and vector density in Rio de Janeiro, Brazil. PLoS Negl Trop Dis (2009) 3:e545. doi:10.1371/journal.pntd.0000545

39. Balmaseda A, Standish K, Mercado JC, Matute JC, Tellez Y, Saborío S, et al. Trends in patterns of dengue transmission over 4 years in a pediatric cohort study in Nicaragua. J Infect Dis (2010) 201:5-14. doi:10.1086/648592

40. Reyes M, Mercado JC, Standish K, Matute JC, Ortega O, Moraga B, et al. Index cluster study of dengue virus infection in Nicaragua. Am J Trop Med Hyg (2010) 83:683-9. doi:10.4269/ajtmh.2010.10-0023

41. Gordon A, Kuan G, Mercado JC, Gresh L, Avilés W, Balmaseda A, et al. The Nicaraguan pediatric dengue cohort study: incidence of inapparent and symptomatic dengue virus infections, 2004-2010. PLoS Negl Trop Dis (2013) 7:e2462. doi:10.1371/journal.pntd.0002462

42. Montoya M, Gresh L, Mercado JC, Williams KL, Vargas MJ, Gutierrez G, et al. Symptomatic versus inapparent outcome in repeat dengue virus infections is influenced by the time interval between infections and study year. PLoS Negl Trop Dis (2013) 7:e2357. doi:10.1371/journal.pntd.0002357

43. Dussart P, Baril L, Petit L, Beniguel L, Quang LC, Ly S, et al. Clinical and virological study of dengue cases and the members of their households: the multinational DENFRAME project. PLoS Negl Trop Dis (2012) 6:e1482. doi:10.1371/journal.pntd.0001482

44. Chau TN, Hieu NT, Anders KL, Wolbers M, Lien Le B, Hieu LT, et al. Dengue virus infections and maternal antibody decay in a prospective birth cohort study of Vietnamese infants. J Infect Dis (2009) 200:1893-900. doi:10.1086/ 648407

45. Pengsaa K, Limkittikul K, Yoksan S, Wisetsing P, Sabchareon A. Dengue antibody in Thai children from maternally transferred antibody to acquired infection. Pediatr Infect Dis J (2011) 30:897-900. doi:10.1097/INF. 0b013e31821f07f6

46. Libraty DH, Acosta LP, Tallo V, Segubre-Mercado E, Bautista A, Potts JA, et al. A prospective nested case-control study of dengue in infants: rethinking and refining the antibody-dependent enhancement dengue hemorrhagic fever model. PLoS Med (2009) 6:e1000171. doi:10.1371/journal.pmed.1000171

47. Capeding RZ, Brion JD, Caponpon MM, Gibbons RV, Jarman RG, Yoon IK, et al. The incidence, characteristics, and presentation of dengue virus infections during infancy. Am J Trop Med Hyg (2010) 82:330-6. doi:10.4269/ajtmh. 2010.09-0542

48. Fukunaga T, Okuno Y, Tadano M, Fukai K. A retrospective serological study of Japanese who contracted dengue fever in Thailand. Biken J (1983) 26:67-74.

49. Cobelens FG, Groen J, Osterhaus AD, Leentvaar-Kuipers A, Wertheim-van Dillen PM, Kager PA. Incidence and risk factors of probable dengue virus infection among Dutch travellers to Asia. Trop Med Int Health (2002) 7:331-8. doi:10.1046/j.1365-3156.2002.00864.x

50. Baaten GG, Sonder GJ, Zaaijer HL, van Gool T, Kint JA, van den Hoek A. Travelrelated dengue virus infection, The Netherlands, 2006-2007. Emerg Infect Dis (2011) 17:821-8. doi:10.3201/eid1705.101125

51. Ratnam I, Black J, Leder K, Biggs BA, Matchett E, Padiglione A, et al. Incidence and seroprevalence of dengue virus infections in Australian travellers to Asia. Eur J Clin Microbiol Infect Dis (2012) 31:1203-10. doi:10.1007/s10096-0111429-1

52. Morrison AC, Minnick SL, Rocha C, Forshey BM, Stoddard ST, Getis A, et al. Epidemiology of dengue virus in Iquitos, Peru 1999 to 2005: interepidemic and epidemic patterns of transmission. PLoS Negl Trop Dis (2010) 4:e670. doi:10.1371/journal.pntd.0000670

53. Barnes WJ, Rosen L. Fatal hemorrhagic disease and shock associated with primary dengue infection on a Pacific Island. Am J Trop Med Hyg (1974) 23:495-506.

54. Guzmán MG, Kouri GP, Bravo J, Soler M, Vazquez S, Morier L. Dengue hemorrhagic fever in Cuba, 1981: a retrospective seroepidemiologic study. Am J Trop Med Hyg (1990) 42:179-84.

55. Guzmán MG, Kouri G, Valdes L, Bravo J, Alvarez M, Vazques S, et al. Epidemiologic studies on dengue in Santiago de Cuba, 1997. Am J Epidemiol (2000) 152:793-9. doi:10.1093/aje/152.9.793

56. Likosky WH, Calisher CH, Michelson AL, Correa-Coronas R, Henderson BE, Feldman RA. An epidemiologic study of dengue type 2 in Puerto Rico, 1969. Am J Epidemiol (1973) 97:264-75.

57. Rodriguez-Figueroa L, Rigau-Perez JG, Suarez EL, Reiter P. Risk factors for dengue infection during an outbreak in Yanes, Puerto Rico in 1991. Am J Trop Med Hyg (1995) 52:496-502.

58. Waterman SH, Novak RJ, Sather GE, Bailey RE, Rios I, Gubler DJ. Dengue transmission in two Puerto Rican communities in 1982. Am J Trop Med Hyg (1985) 34:625-32.

59. Balmaseda A, Hammond SN, Tellez Y, Imhoff L, Rodriguez Y, Saborío SI, et al. High seroprevalence of antibodies against dengue virus in a prospective study of schoolchildren in Managua, Nicaragua. Trop Med Int Health (2006) 11:935-42. doi:10.1111/j.1365-3156.2006.01641.x

60. Van Benthem BH, Vanwambeke SO, Khantikul N, Burghoorn-Maas C, Panart $\mathrm{K}$, Oskam L, et al. Spatial patterns of and risk factors for seropositivity for dengue infection. Am J Trop Med Hyg (2005) 72:201-8.

61. Halstead SB, Udomsakdi S, Singharaj P, Nisalak A. Dengue and chikungunya virus infection in man in Thailand, 1962-1964. 3. Clinical, epidemiologic, and virologic observations on disease in non-indigenous white persons. Am J Trop Med Hyg (1969) 18:984-96.

62. Sharp TW, Wallace MR, Hayes CG, Sanchez JL, DeFraites RF, Arthur RR, et al. Dengue fever in U.S. troops during operation restore hope, Somalia, 1992-1993. Am J Trop Med Hyg (1995) 53:89-94.

63. Potasman I, Srugo I, Schwartz E. Dengue seroconversion among Israeli travelers to tropical countries. Emerg Infect Dis (1999) 5:824-7. doi:10.3201/eid0506. 990615

64. Seet RC, Ooi EE, Wong HB, Paton NI. An outbreak of primary dengue infection among migrant Chinese workers in Singapore characterized by prominent 
gastrointestinal symptoms and a high proportion of symptomatic cases. J Clin Virol (2005) 33:336-40. doi:10.1016/j.jcv.2005.03.002

65. CDC. Dengue virus infection among travellers returning from Haiti - Georgia and Nebraska, October 2010. MMWR Morb Mortal Wkly Rep (2011) 60:914-7.

66. Olkowski S, Forshey BM, Morrison AC, Rocha C, Vilcarromero S, Halsey ES, et al. Reduced risk of disease during postsecondary dengue virus infections. $J$ Infect Dis (2013) 208:1026-33. doi:10.1093/infdis/jit273

67. Halstead SB, O’Rourke EJ. Dengue viruses and mononuclear phagocytes. I. Infection enhancement by non-neutralizing antibody. J Exp Med (1977) 146:201-17. doi:10.1084/jem.146.1.201

68. Kliks SC, Nimmanitya S, Nisalak A, Burke DS. Evidence that maternal dengue antibodies are important in the development of dengue hemorrhagic fever in infants. Am J Trop Med Hyg (1988) 38:411-9.

69. Siler JF, Hall MW, Hitchens AP. Dengue. Its history, epidemiology, mechanism of transmission, etiology, clinical manifestations, immunity, and prevention. Philippine J Sci (1926) 29:1-304.

70. Simmons JS, St. John JH, Reynolds FHK. Experimental studies of dengue. Philippine J Sci (1931) 44:1-247.

71. LeDuc JW, Esteves K, Gratz NG. Dengue and dengue haemorrhagic fever. In: Murray CJ, Lopez AD, Mathers CD, editors. The Global Epidemiology of Infectious Diseases. Vol. IV. Global Burden of Disease and Injury Series. Geneva: World Health Organization (2004). p. 219-42.

72. de la C Sierra B, Kouri G, Guzmán MG. Race: a risk factor for dengue hemorrhagic fever. Arch Virol (2007) 152:533-42. doi:10.1007/s00705-006-0869-x

73. Coffey LL, Mertens E, Brehin AC, Fernandez-Garcia MD, Amara A, Després $\mathrm{P}$, et al. Human genetic determinants of dengue virus susceptibility. Microbes Infect (2009) 11:143-56. doi:10.1016/j.micinf

74. Khor CC, Chau TN, Pang J, Davila S, Long HT, Ong RT, et al. Genome-wide association study identifies susceptibility loci for dengue shock syndrome at MICB and PLCE1. Nat Genet (2011) 43:1139-41. doi:10.1038/ng.981

75. García G, Sierra B, Pérez AB, Aguirre E, Rosado I, Gonzalez N, et al. Asymptomatic dengue infection in a Cuban population confirms the protective role of the RR variant of the Fc $\gamma$ RIIa polymorphism. Am J Trop Med Hyg (2010) 82:1153-6. doi:10.4269/ajtmh.2010.09-0353

76. Sabin A. Research on dengue during world war II. Am J Trop Med Hyg (1952) 1:30-50.

77. Salje H, Lessler J, Endy T, Curriero F, Gibbons R, Nisalak A, et al. Revealing the microscale spatial signature of dengue transmission and immunity in an urban population. Proc Natl Acad Sci U S A (2012) 109:9535-8. doi:10.1073/pnas.1120621109

78. Stollenwerk N, Aguiar M, Ballesteros S, Boto J, Kooi B, Mateus L. Dynamic noise, chaos and parameter estimation in population biology. Interface Focus (2012) 2:156-69. doi:10.1098/rsfs.2011.0103

79. Reich NG, Shrestha S, King AA, Rohani P, Lessler J, Kalayanarooj S, et al. Interactions between serotypes of dengue highlight epidemiological impact of crossimmunity. J R Soc Interface (2013) 10:20130414. doi:10.1098/rsif.2013.0414

80. OhAinle M, Balmaseda A, Macalalad AR, Tellez Y, Zody MC, Saborío S, et al. Dynamics of dengue disease severity determined by the interplay between viral genetics and serotype-specific immunity. Sci Transl Med (2011) 3:114-28. doi:10.1126/scitranslmed.3003084

81. Gubler DJ, Reed D, Rosen L, Hitchcock JR Jr. Epidemiologic, clinical, and virologic observations on dengue in the Kingdom of Tonga. Am J Trop Med Hyg (1978) 27:581-9.

82. Vaughn D, Green S, Kalayanarooj S, Innis B, Nimmannitya S, Suntayakorn $S$, et al. Dengue viremia titer, antibody response pattern and virus serotype correlate with disease severity. J Infect Dis (2000) 181:2-9. doi:10.1086/315215

83. Rico-Hesse R. Dengue virus virulence and transmission determinants. Curr Top Microbiol Immunol (2010) 338:45-55. doi:10.1007/978-3-642-02215-9_4

84. Halstead SB. Neutralization and antibody-dependent enhancement of dengue viruses. Adv Virus Res (2003) 60:421-67. doi:10.1016/S0065-3527(03)60011-4

85. OhAinle M, Harris E. Dengue pathogenesis: viral factors. 2nd ed. In: Gubler DJ, Ooi EE, Vasudevan S, Farrar J, editors. Dengue and Dengue Hemorrhagic Fever. Wallingford: CAB International (2014). p. 231-50.

86. Domingo E, Holland JJ. RNA virus mutations and fitness for survival. Annu Rev Microbiol (1997) 51:151-78. doi:10.1146/annurev.micro.51.1.151

87. Craig S, Thu HM, Lowry K, Wang XF, Holmes EC, Aaskov J. Diverse dengue type 2 virus populations contain recombinant and both parental viruses in a single mosquito host. J Virol (2003) 77:4463-7. doi:10.1128/JVI.77.7.44634467.2003
88. Wittke V, Robb TE, Thu HM, Nisalak A, Nimmannitya S, Kalayanrooj S, et al. Extinction and rapid emergence of strains of dengue 3 virus during an interepidemic period. Virology (2002) 301:148-56. doi:10.1006/viro.2002.1549

89. Aaskov J, Buzacott K, Thu HM, Lowry K, Holmes EC. Long-term transmission of defective RNA viruses in humans and Aedes mosquitoes. Science (2006) 311:236-8. doi:10.1126/science.1115030

90. Lin SR, Hsieh SC, Yueh YY, Lin TH, Chao DY, Chen WJ, et al. Study of sequence variation of dengue type 3 virus in naturally infected mosquitoes and human hosts: implications for transmission and evolution. J Virol (2004) 78:12717-21. doi:10.1128/JVI.78.22.12717-12721.2004

91. Descloux E, Cao-Lormeau VM, Roche C, De Lamballerie X. Dengue 1 diversity and microevolution, French polynesia 2001-2006: connection with epidemiology and clinics. PLoS Negl Trop Dis (2009) 3:e493. doi:10.1371/journal.pntd. 0000493

92. Thai KT, Henn MR, Zody MC, Tricou V, Nguyet NM, Charlebois P, et al. Highresolution analysis of intrahost genetic diversity in dengue virus serotype 1 infection identifies mixed infections. J Virol (2012) 86:835-43. doi:10.1128/ JVI.05985- 11

93. Parameswaran P, Charlebois P, Tellez Y, Nunez A, Ryan EM, Malboeuf CM, et al. Genome-wide patterns of intrahuman dengue virus diversity reveal associations with viral phylogenetic clade and interhost diversity. J Virol (2012) 86:8546-58. doi:10.1128/JVI.00736-12

94. Guzmán MG, Kourí G, Halstead SB. Do escape mutants explain rapid increases in dengue case-fatality rates within epidemics? Lancet (2000) 355:1902-3. doi:10.1016/S0140-6736(00)02303-5

95. Chao DY, Lin TH, Hwang KP, Huang JH, Liu CC, King CC. 1998 Dengue hemorrhagic fever epidemic in Taiwan. Emerg Infect Dis (2004) 10:552-4. doi:10.3201/eid1003.020518

96. Rodriguez-Roche R, Alvarez M, Gritsun T, Halstead S, Kouri G, Gould EA, et al. Virus evolution during a severe dengue epidemic in Cuba, 1997. Virology (2005) 334:154-9. doi:10.1016/j.virol.2005.01.037

97. Holmes EC, Worobey M, Rambaut A. Phylogenetic evidence for recombination in dengue virus. Mol Biol Evol (1999) 16:405-9. doi:10.1093/oxfordjournals. molbev.a026121

98. Domingo C, Palacios G, Jabado O, Reyes N, Niedrig M, Gascón J, et al. Use of a short fragment of the C-terminal $\mathrm{E}$ gene for detection and characterization of two new lineages of dengue virus 1 in India. J Clin Microbiol (2006) 44:1519-29. doi:10.1128/JCM.44.4.1519-1529.2006

99. Gubler DJ, Rosen L. Variation among geographic strains of Aedes albopictus in susceptibility to infection with dengue viruses. Am J Trop Med Hyg (1976) 25:318-25.

100. Lambrechts L, Fansiri T, Pongsiri A, Thaisomboonsuk B, Klungthong C, Richardson JH, et al. Dengue-1 virus clade replacement in Thailand associated with enhanced mosquito transmission. J Virol (2012) 86:1853-61. doi:10.1128/JVI.06458-11

101. Nguyet MN, Duong TH, Trung VT, Nguyen TH, Tran CN, Long VT, et al. Host and viral features of human dengue cases shape the population of infected and infectious Aedes aegypti mosquitoes. Proc Natl Acad Sci U S A (2013) 110:9072-7. doi:10.1073/pnas.1303395110

102. Rodriguez-Barraquer I, Mier-y-Teran-Romero L, Burke DS, Cummings DA. Challenges in the interpretation of dengue vaccine trial results. PLoS Negl Trop Dis (2013) 7:e2126. doi:10.1371/journal.pntd.0002126

Conflict of Interest Statement: The authors declare that the research was conducted in the absence of any commercial or financial relationships that could be construed as a potential conflict of interest.

Received: 08 April 2014; accepted: 28 May 2014; published online: 11 June 2014. Citation: Grange L, Simon-Loriere E, Sakuntabhai A, Gresh L, Paul R and Harris E (2014) Epidemiological risk factors associated with high global frequency of inapparent dengue virus infections. Front. Immunol. 5:280. doi: 10.3389/fimmu.2014.00280 This article was submitted to Microbial Immunology, a section of the journal Frontiers in Immunology.

Copyright (c) 2014 Grange, Simon-Loriere, Sakuntabhai, Gresh, Paul and Harris. This is an open-access article distributed under the terms of the Creative Commons Attribution License (CC BY). The use, distribution or reproduction in other forums is permitted, provided the original author(s) or licensor are credited and that the original publication in this journal is cited, in accordance with accepted academic practice. No use, distribution or reproduction is permitted which does not comply with these terms. 